\title{
Influence of Heat Treatment on the Corrosion of Microalloyed Steel in Sodium Chloride Solution
}

\author{
Asiful Hossain Seikh \\ Centre of Excellence for Research in Engineering Materials, King Saud University, P.O. Box 800, Riyadh 11421, Saudi Arabia \\ Correspondence should be addressed to Asiful Hossain Seikh; asifuls@gmail.com
}

Received 28 May 2013; Revised 19 September 2013; Accepted 19 September 2013

Academic Editor: Hassan Arida

Copyright (C) 2013 Asiful Hossain Seikh. This is an open access article distributed under the Creative Commons Attribution License, which permits unrestricted use, distribution, and reproduction in any medium, provided the original work is properly cited.

Microalloyed Steels find wide application in car bodies and other engineering parts because of its high strength as well as high ductility. Very fine grained microstructure is the reason behind the combination of strength and ductility. It has been reported that repeated quenching leads to further refining of microstructure. In the present investigation, corrosion resistance property of E34 microalloy steel has been studied in $3.5 \% \mathrm{NaCl}$ solution in different microstructural conditions such as the as rolled one and three repeated quenched conditions. Weight loss, potentiodynamic polarization method, and electrochemical impedance spectroscopy (EIS) techniques have been used. To reveal the corrosion resistance of different treated steels, some significant characterization parameters such as $E_{\text {corr }}, I_{\text {corr }}, R_{p}$, and $R_{\mathrm{ct}}$ in linear polarization and EIS curves were analyzed and compared. It is found that with repeated recrystallization grains become finer, and corrosion rate increases suggesting that a compromise has to strike between high mechanical property and corrosion rate.

\section{Introduction}

Microalloyed Steels finds wide applications including automobile frames, gas transmission pipelines, ship plates, bridge beams, and electrical power transmission poles because of its high strength as well as high ductility. Microalloyed pipeline steels are extensively used in the oil and gas industry and have severe mechanical requirements for sour service applications and deep water gas wells. Microalloyed steel has a ferritic matrix that is of a mild steel but with an extremely fine grained structure. Very fine grain structure of this steel is due to the combination of high strength and ductility. This combination is given through the addition of microalloying elements such as $\mathrm{Mo}, \mathrm{Ti}, \mathrm{V}, \mathrm{Ni}$, and $\mathrm{Nb}$; and also due to thermomechanical heat treatments [1-3]. Alloying additions of these alloying elements of the order of microadditions brings this refinement in the microstructure. These microalloying elements improve the strength properties due to fine precipitation within the grains in addition to the solute drag effect in the hardenability of the steels due to the reduction of grain coarsening during heating. On the other hand, it has been reported that without change in other microconstitutional properties, the grain refinement of ferritic microalloyed steels is done by repeated quenching from a temperature just below the lower critical temperature, that is, in the ferritic region as reported in the literature $[4,5]$. Corrosion behavior of steel and the effects of microstructure on such behavior are still an open field for investigation to correlate the metallurgical concept with the corrosion parameters. Due to environmental and economical effects, the steel corrosion is considered as a major industrial problem that costs hundreds of billions of dollars [6]. Corrosion of structural elements is a major issue for any industry due to the chemical environment of chemical processing. Several industries used acid solutions for cleaning, pickling, descaling, and acidizing processes by which steels come in contact with acids. Only few authors [7-9] have investigated the influence of heat treatment on the corrosion behavior of steel in different solution.

In the present study, corrosion property of as rolled and repeatedly quenched microalloyed steels in $3.5 \% \mathrm{NaCl}$ solution has been studied by weight loss, potentiodynamic polarization method, and electrochemical impedance spectroscopy (EIS) techniques. 


\section{Experimental}

2.1. Materials. The materials are commonly called $\mathrm{Nb}$ bearing commercial microalloyed steel E-34 grades with chemical composition (weight $\%$ ) Fe, $0.060 \mathrm{C}, 0.57 \mathrm{Mn}, 0.008 \mathrm{~S}$, $0.012 \mathrm{P}, 0.020 \mathrm{Si}, 0.055 \mathrm{Al}$, and $0.012 \mathrm{Nb}$.

2.2. Heat Treatment. Four numbers of square-section specimen strips of size $(10 \mathrm{~mm} \times 10 \mathrm{~mm} \times 5 \mathrm{~mm})$ were cut out with the help of a hack saw from the hot rolled steel plate keeping the long axis of the strips parallel to the rolling direction as determined from the metallographic analysis of the as received microalloyed steel plate and were prepared for heat treatment after grinding in a wheel.

For grain refinement of the ferritic microalloyed steels, repeated quench from a temperature just below the lower critical temperature was adopted [4]. In the heat treatment, firstly, set the furnace at a temperature of $600^{\circ} \mathrm{C}$, just below the lower critical temperature. Out of 4 samples, 3 samples were kept in the furnace at a temperature of $600^{\circ} \mathrm{C}$, just below the lower critical temperature and heated at the scheduled temperature for 45 minutes to get uniform heating of the entire cross-section. After that the samples were taken outside and immediately put into a water bath. The samples were quenched until the temperature came down to room temperature. Now, 1 sample was taken out, and 2 others were heat treated in similar way, out of which 1 was taken out and another 1 was treated again in same way. During cooling in the quenching bath, continuous stirring of the bath has been carried out in all the treatment cycles for uniform heat transfer.

All heat treatment cycles were carried out in a Muffle Furnace coupled with a proportional temperature controller with an accuracy level of $\pm 20^{\circ} \mathrm{C}$. The furnace atmosphere was not controlled.

2.3. Sample Preparation. One of the surfaces of each of the metallographic specimens as received (designates as AR), first quench (designates as Q1), second quench (designates as Q2), and third quench (designates as Q3) of each grade was grounded mechanically on the silicon carbide abrasive papers sequentially on $60,120,240,320,400$, and 600 grit silicon carbide papers and polished on a Selvyt cloth using coarse and fine Geosyn-Grade I slurry of $\mathrm{Al}_{2} \mathrm{O}_{3}$. Specimens were cleaned, washed by water and then by alcohol, and dried. All the polished specimens were etched using $2 \%$ nital solution $\left(2 \% \mathrm{HNO}_{3}\right.$ in Methanol). With these polished and etched samples, optical microscopy, grain size measurement, and hardness testing were carried out.

2.4. Optical Microscopy, Grain Size Measurement, and Hardness Testing. The etched specimens were tested one by one using an optical microscope. The photographs of the microstructure were taken with help of a Camera fitted with a microscope.

The grain size of each specimen was measured by using a real image analysis with the help of an image analyzing software, Biovis Material Plus-version 1.3.
Vickers hardness of the metallographic specimens was carried out in a standard Vickers hardness testing machine using square-base diamond pyramid as the indenter and a load of $30 \mathrm{~kg}$ as per ASTM Standard E92-72. Tests were carried out at least in three different positions on the polished surface of the specimens, and the average Vickers hardness value was reported.

2.5. Solution Preparation. Experiments were done in stagnant $3.5 \% \mathrm{NaCl}$ solution. The solution was prepared from analytical grade reagents and distilled water. While the electrolyte solutions were in equilibrium with the atmosphere, all experiments were carried out under thermostatic conditions $25^{\circ} \mathrm{C}$ $\left( \pm 0.1^{\circ} \mathrm{C}\right)$.

\subsection{Experimental Procedure}

2.6.1. Weight Loss Measurement. Microalloyed steel specimens of dimension $10 \mathrm{~mm} \times 10 \mathrm{~mm} \times 5 \mathrm{~mm}$ were cut abraded with various grades of silicon carbide papers $(200,400,600$, 800 , and 1000). The exact area and thickness of each coupon were measured and washed with distilled water containing detergent. Specimens were then degreased again with acetone and finally dried. After weighing with sensitive electronic balance, specimens were immersed in $50 \mathrm{~mL} 3.5 \% \mathrm{NaCl}$ solutions (nondeaerated) at room temperature. Weight loss of metal specimens was noted at every $24 \mathrm{~h}$ time interval for five days. The experiments were carried out in duplicate, and the average values were reported. We carried out immersion test in accordance with ASTM G31-72. The corrosion rate $(\nu)$ is calculated by the following equation [10];

$$
v=\frac{W}{S t},
$$

where $W$ is the average weight loss of coupon, $S$ is the total area of specimen, and $t$ is the time of treatment.

2.6.2. Linear Polarization and EIS Measurement. Linear polarization and the EIS were performed in a conventional three-electrode cell in which $\mathrm{Ag} / \mathrm{AgCl}$ was the reference electrode, platinum foil was the counter electrode, and the steel strip was the working electrode (WE). All potentials quoted in this paper were referred to the $\mathrm{Ag} / \mathrm{AgCl}$.

As introduced before, the strips of E-34 grade with differently treated conditions were used as working electrode. Specimens were machined into a cuboidal form with an exposed area $1 \mathrm{~cm}^{2}$. An insulated copper wire was secured to one of the surfaces of each steel specimen with solder at low temperature. The specimens were mounted with epoxide resin in such a way that only the other flat surface contacted with the solution. This flat surface of each specimen was polished mechanically in a graded emery paper, and final finish was given on a polishing wheel using alumina powder. The polished surface was then thoroughly washed and digressed in ethanol before use and dried at room temperature.

Corrosion tests were carried out by using an Autolab Potentiostat (PGSTAT20 computer controlled) operated by the general purpose electrochemical software (GPES) version 
4.9. The free corrosion potential (versus $\mathrm{Ag} / \mathrm{AgCl}$ ) was followed after immersing the working electrode in the test solution until the potential stabilized within $\pm 1 \mathrm{mV}$. This was followed by electrochemical impedance spectroscopy test; EIS data were recorded for the steel specimens at corrosion potentials $\left(E_{\text {corr }}\right)$ after 60 mins immersion in the test solution. The frequency was scanned from $100 \mathrm{KHz}$ to $100 \mathrm{mHz}$, with an ac wave of $\pm 5 \mathrm{mV}$ peak-to-peak overlaid on a dc bias potential to get Nyquist and bode plots. The best equivalent circuit of Nyquist plots was calculated by fit and simulation method. The linear potentiodynamic polarization curves were obtained by scanning the potential in the forward direction from -0.1 to $0.1 \mathrm{~V}$ against $\mathrm{Ag} / \mathrm{AgCl}$ at a scan rate of $1 \mathrm{mV} / \mathrm{s}$.

All the electrochemical experiments were recorded after immersion of the electrode in the test solution for 60 mins at a temperature of $(25 \pm 1)^{\circ} \mathrm{C}$. Fresh solution and fresh steel samples were used after each sweep. For each experimental condition, two to three measurements were performed to ensure the reliability and reproducibility of the data.

\section{Results and Discussions}

3.1. Metallographic Studies of the Microalloyed Steel. Figure 1 shows the microstructure of (a) as received, (b) first quench, (c) second quench, and (d) third quenched BSK 46 (the magnifications for all specimens were $4 \times 40 \mathrm{x}$ ). The variation of the grain size number with the change of the quenching temperature is also listed in Table 1. It is clearly seen from Figure 1 that the grain size is bigger for the as received sample and gets finer with quenching and further with repeating the number of quenching up to the third time. The numerical values of the grain size recorded in Table 1 in addition to the images shown in Figure 1 confirm that the ferritic grain size decreases with repeating the quench from first to third quench. Here, the ASTM grain size number of the as received sample was reported to be 10.0 , increased due to first quenching to 10.5 , and further increased to 10.8 for second quenching and finally recorded the highest value, 11.0, with repeating the process to the third quenching. This is because the repeated quenching leads to repeated recrystallization, which in turn leads to producing new grains at the expense of others, and a coarse grained material (as rolled) replaces the fine grained recrystallized structure. This concludes that increasing the repeated quenching increases the ASTM grain size number and therefore decreases the grain size.

The variation of the Vickers hardness number (VHN) for the test specimens with the number of the repeated quenching is listed in Table 2. It is shown from Table 2 that the hardness values for the as received E-34 sample recorded $146 \mathrm{VHN}$. This value increased to $167 \mathrm{VHN}, 170 \mathrm{VHN}$, and 172 VHN when the repeated quenching for the tested specimen was increased from first quench to second quench and further to third quench sample, respectively. This increase in the hardness values with increasing the repeated quenching is attributed to the grain refinement of the ferritic microalloyed E-34 steel. So from this, it can be concluded that due to
TABLE 1: ASTM grain size number for the tested specimens.

\begin{tabular}{lccc}
\hline As received & First quench & Second quench & Third quench \\
\hline 10.0 & 10.5 & 10.8 & 11.0 \\
\hline
\end{tabular}

TABLE 2: Vickers hardness number (VHN) for the test specimens.

\begin{tabular}{lccc}
\hline As received & First quench & Second quench & Third quench \\
\hline 146 & 167 & 170 & 172
\end{tabular}

TABLE 3: Corrosion rate in $\left(\mathrm{mg} \mathrm{cm}^{-2} \mathrm{~h}^{-1}\right)$ data obtained from weight loss measurements for different microalloy steel in $3.5 \% \mathrm{NaCl}$ solutions at room temperature.

\begin{tabular}{lccc}
\hline \multicolumn{4}{c}{ Corrosion rates in $\left(\mathrm{mg} \mathrm{cm}^{-2} \mathrm{~h}^{-1}\right)$ at $3.5 \% \mathrm{NaCl}$} \\
As received & First quench & Second quench & Third quench \\
\hline 6.33 & 9.72 & 11.21 & 13.84 \\
\hline
\end{tabular}

repeated quenching grain refinement of ferritic microalloyed steels can be achieved.

3.2. Weight Loss Measurements. Table 3 presents the values of the corrosion rates (in $\mathrm{mg} \mathrm{cm}^{-2} \mathrm{~h}^{-1}$ ) derived from weight loss measurements, for different microalloy steel after 5 hours of immersion in $3.5 \% \mathrm{NaCl}$ solutions at room temperature. It is observed that the samples lose weight with increasing exposure time; trend of weight loss is increasing order of as received, first quench, second quench, and third quench samples. The observed increase in cumulative weight loss of the samples at constant temperature agrees with the observation earlier made that corrosion rate at constant temperature increases with increasing exposure time, while the observed variation in the weight loss of the sample may be attributed to difference in the samples grain size [11]. It was equally revealed that heat treatment affects rate of corrosion and posited that the bigger the grains of a material, the more are its resistance to corrosion [12]. Hence, the as received sample with the biggest grain size distribution revealed less weight loss as compared to the repeated quenched samples.

3.3. Potentiodynamic Polarization Measurements. The polarization curves for microalloy steel specimens (As received $(\mathrm{AR})$, first quench $(\mathrm{Q} 1)$, second quench $(\mathrm{Q} 2)$, and third quench (Q3)) in 3.5\% NaCl at room temperature are shown in Figure 2. Polarization parameters obtained from the curves are as shown in Table 4. These parameters include the values of corrosion current densities $\left(I_{\text {corr }}\right)$, corrosion potential $\left(E_{\text {corr }}\right)$, cathodic Tafel slope $\left(b_{c}\right)$, anodic Tafel slope $\left(b_{a}\right)$, and polarization resistance $\left(R_{p}\right)$. The corrosion current density $I_{\text {corr }}$ was determined graphically by extrapolating the cathodic and anodic Tafel slopes to the $E_{\text {corr }}$ (versus $\mathrm{Ag} / \mathrm{AgCl}$ ) as shown in Figure 3 in case of as received (AR) sample. From the slope analysis of the linear polarization curves in the vicinity of corrosion potential, the values of polarization resistance $\left(R_{p}\right)$ in $3.5 \% \mathrm{NaCl}$ solution were obtained.

From polarization data, it is found that $E_{\text {corr }}$ (versus $\mathrm{Ag} / \mathrm{AgCl}$ ) values shifted towards more cathodic (negative) 


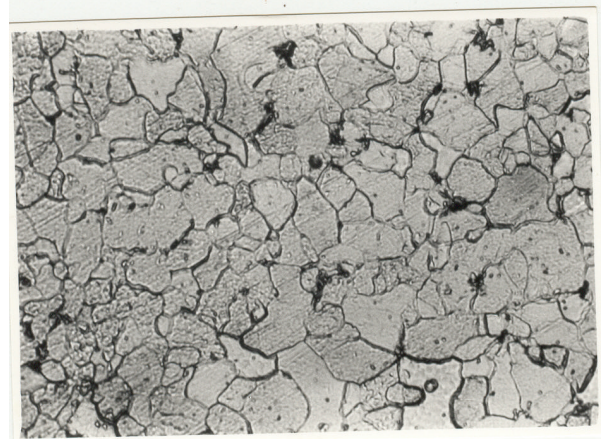

(a)

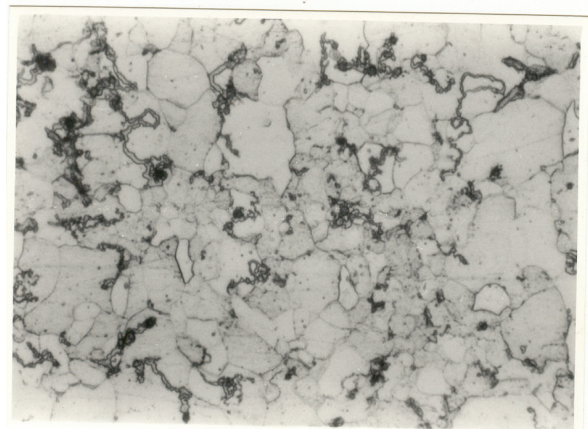

(c)

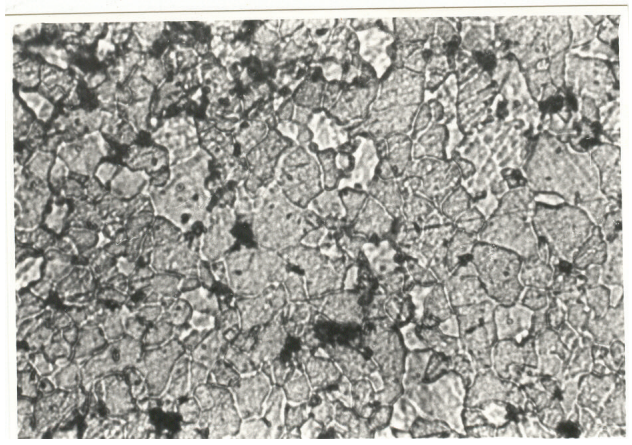

(b)

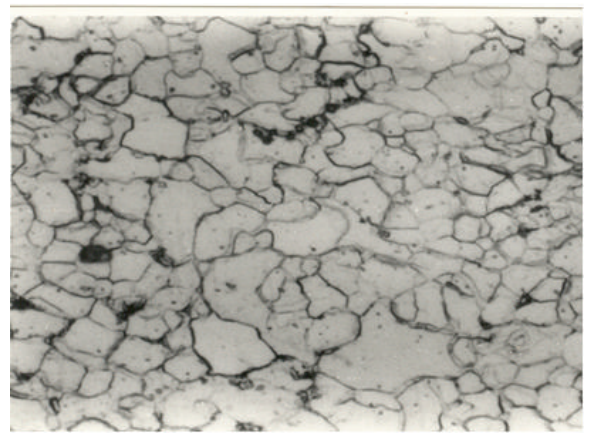

(d)

FIGURE 1: The microstructure of (a) as received, (b) first quench, (c) second quench, and (d) third quenched E-34; all magnifications were $4 \times 40 \mathrm{x}$.

TABle 4: Potentiodynamic polarization parameters of microalloy steel samples in $3.5 \% \mathrm{NaCl}$ at room temperature.

\begin{tabular}{|c|c|c|c|c|c|}
\hline & \multicolumn{4}{|c|}{ Tafel data } & \multirow{2}{*}{$\begin{array}{l}\text { Linear polarization data } \\
\qquad R_{p} \Omega\end{array}$} \\
\hline & $b_{a} / \mathrm{mV} /$ decade & $b_{c} / \mathrm{mV} /$ decade & $E_{\text {corr }} \mathrm{mV}$ & $I_{\text {corr }} \mu \mathrm{A}$ & \\
\hline As received & 64.68 & 36.35 & -539 & 2.3645 & 973.9 \\
\hline First quench & 60.62 & 50.48 & -629 & 4.8089 & 758.6 \\
\hline Second quench & 85.43 & 54.87 & -664 & 5.0893 & 689.4 \\
\hline Third quench & 62.64 & 49.37 & -692 & 11.086 & 594.6 \\
\hline
\end{tabular}

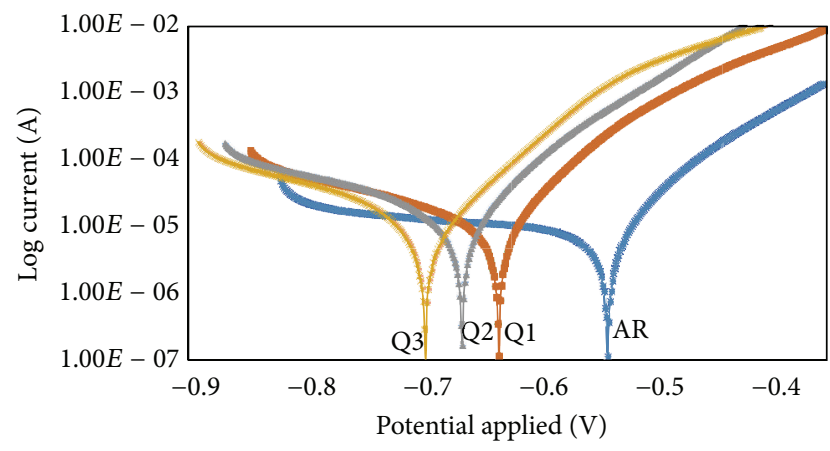

Figure 2: Potentiodynamic polarization curves for microalloy steel samples in $3.5 \% \mathrm{NaCl}$ at room temperature (AR-as received, Q1-first quench, Q2-second quench, and Q3-third quench).

region, and $I_{\text {corr }}$ values increases as we go for repeated quenching. Grain refinement achieved in repeated quenching renders greater anodic area than coarser grained structure

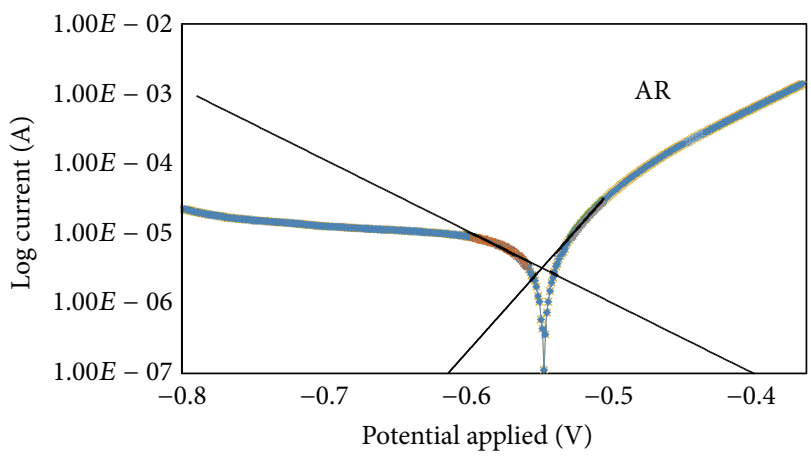

FIGURE 3: Determination of polarization parameters by Tafel extrapolation method (e.g., as received sample).

[6]. Hence, corrosion rate increases and polarization resistance $\left(R_{p}\right)$ decreases due to repeated quenching.

In steel, when oxygen is present, iron is oxidized at the anodic site and releases electrons (see (2)). At the 
cathode, oxygen combines with moisture, and the electrons are released at the anode to form hydroxyl ions (see (3))

$$
\begin{gathered}
\mathrm{Fe} \longrightarrow \mathrm{Fe}^{2+}+2 \mathrm{e}^{-} \\
\frac{1}{2} \mathrm{O}_{2}+\mathrm{H}_{2} \mathrm{O}+2 \mathrm{e}^{-} \longrightarrow 2 \mathrm{OH}^{-}
\end{gathered}
$$

In the presence of chlorides, iron at the anode is oxidized as before (see (2)), and the ferrous ions react with chloride ions to form a soluble iron-chloride complex (see (4)). The ironchloride complex reacts with hydroxyl ions and forms ferrous hydroxide (see (5)), which is a greenish black product;

$$
\begin{gathered}
\mathrm{Fe}^{2+}+2 \mathrm{Cl}^{-} \longrightarrow[\mathrm{FeCl} \text { complex }]^{+} \\
{[\mathrm{FeCl} \text { complex }]^{+}+2 \mathrm{OH}^{-} \longrightarrow \mathrm{Fe}(\mathrm{OH})_{2}+\mathrm{Cl}^{-}} \\
4 \mathrm{Fe}(\mathrm{OH})_{2}+2 \mathrm{H}_{2} \mathrm{O}+\mathrm{O}_{2} \longrightarrow 4 \mathrm{Fe}(\mathrm{OH})_{3} \\
2 \mathrm{Fe}(\mathrm{OH})_{3} \longrightarrow \mathrm{Fe}_{2} \mathrm{O}_{3}+3 \mathrm{H}_{2} \mathrm{O}
\end{gathered}
$$

The ferrous hydroxide is oxidized to ferric hydroxide that, in turn dehydrates to form ferric oxide, as shown in (6) and (7). At the cathode, hydroxyl ions are formed when oxygen combines with moisture, and the electrons are released at the anode as before (see (3)). As demonstrated by (4) and (5), the chloride ions are not consumed and remain available to continue contributing to corrosion. Chloride attack on steel usually occurs as pitting corrosion. Pitting will continue to increase if the chloride content exceeds a specific concentration. This chloride threshold is believed to be dependent on the concentration of hydroxyl ions [13].

Potentiodynamic polarization curves in Figure 2 show no sharp slope in the anodic range, meaning that no passive films are formed on the metal surface [14]. According to the corrosion theory, the shift in the cathodic curves reveals that the corrosion process is mainly accelerated by the cathodic reactions.

3.4. Electrochemical Impedance Spectroscopy (EIS) Measurements. The corrosion response of microalloy steel specimens in $3.5 \% \mathrm{NaCl}$ solution has been investigated using electrochemical impedance spectroscopy at room temperature, and the Bode and Nyquist plots are represented in Figure 4. It is seen from this Figure that the shapes of Nyquist plots for the as received as well as quenched specimens are similar at each concentration, with one depressed semicircle. As can be seen from Figure 4, the Nyquist plots do not yield perfect semicircles as expected from the theory of EIS. The deviation from ideal semicircle was generally attributed to the frequency dispersion [15] as well as to the inhomogeneities of the surface and mass transport resistant [16]. It is evident from the plots that the impedance response of as received steel specimens showed a marked difference with that of quenched samples. The capacitance loop intersects with the real axis at higher and lower frequencies. At high frequency end, the intercept corresponds to the solution resistance $\left(R_{s}\right)$ and at lower frequency end corresponds to the sum of $R_{s}$ and
TABLE 5: Electrochemical impedance parameters of microalloy steel samples in $3.5 \% \mathrm{NaCl}$ at room temperature.

\begin{tabular}{lcccc}
\hline & \multicolumn{4}{c}{ EIS data } \\
& $R_{s} \Omega$ & $\mathrm{CPE}\left(Y_{0}\right) \mu \mathrm{Mho}$ & $n$ & $R_{\mathrm{ct}} \Omega$ \\
\hline As received & 10 & 1080 & 0.863 & 775 \\
First quench & 10 & 1020 & 0.864 & 490 \\
Second quench & 8 & 859 & 0.815 & 440 \\
Third quench & 7 & 768 & 0.833 & 340 \\
\hline
\end{tabular}

charge transfer resistance $\left(R_{\mathrm{ct}}\right)$. The difference between the two values gives $R_{\mathrm{ct}}$. The value of $R_{\mathrm{ct}}$ is a measure of electron transfer across the exposed area of the metal surface, and it is inversely proportional to rate of corrosion [17].

Impedance behaviour can be well explained by pure electric models that could verify and enable to calculate numerical values corresponding to the physical and chemical properties of electrochemical system under examination [18]. The simple equivalent circuit that fits to many electrochemical systems consisting of a parallel combination of a double layer capacitance $\left(C_{\mathrm{dl}}\right)$ and the charge transfer resistance $\left(R_{\mathrm{ct}}\right)$ corresponding to the corrosion reaction at metal/electrolyte interface and the solution resistance $\left(R_{\mathrm{s}}\right)$ between the working and reference electrode $[19,20]$. To reduce the effects due to surface irregularities of metal, constant phase element (CPE) is introduced into the circuit instead of a pure double layer capacitance which gives more accurate fit [21] as shown in Figure 5.

The impedance of CPE can be expressed as

$$
Z_{\mathrm{CPE}}=\frac{1}{Y_{0}}(j \omega)^{n},
$$

where $Y_{0}$ is the magnitude of CPE, $n$ is the exponent (phase shift), $\omega$ is the angular frequency, and $j$ is the imaginary unit. CPE may be resistance, capacitance, and inductance depending upon the values of $n$ [19]. In all experiments, the observed value of $n$ ranges between 0.8 and 1.0, suggesting the capacitive response of CPE.

The EIS parameters such as $R_{\mathrm{ct}}, R_{s}$, and CPE are listed in Table 5 indicating that the values of $R_{\mathrm{ct}}$ are found to decrease with repeated quenching. These observations support the idea that the corrosion of steel is controlled by a charge transfer process [22]. Bode plots shown in Figure 4 indicates the presence of one time constant, corresponding to one depressed semicircle that was obtained in case of Nyquist plots.

The corrosion resistance, calculated from EIS results, shows the same trend as those obtained from polarization measurements. The difference in corrosion resistance of the two methods may be due to the different surface status of the electrode in two measurements. EIS were performed at the rest potential, while in polarization measurements the electrode potential was polarized to high over potential, nonuniform current distributions, resulted from cell geometry, solution conductivity, counter and reference electrode placement, and so forth, will lead to the difference between the electrode area actually undergoing polarization and the total area [23]. 


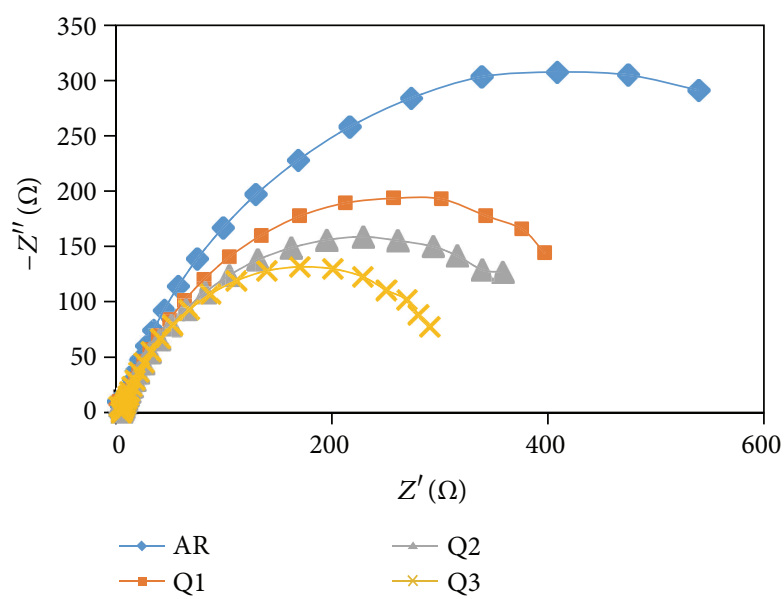

(a)

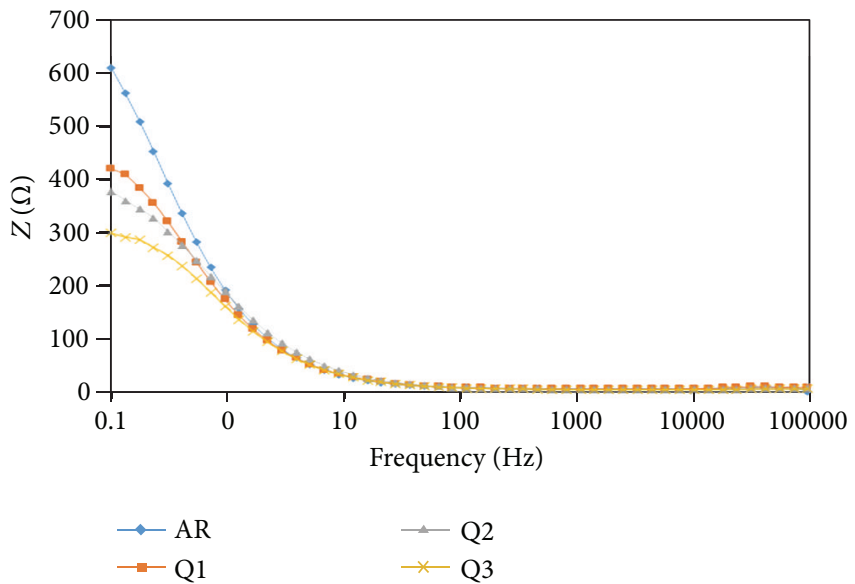

(b)

Figure 4: Electrochemical Impedance curves (Nyquist and Bode) for microalloy steel samples in 3.5\% NaCl at room temperature (AR-as received, Q1-first quench, Q2-second quench, and Q3-third quench).

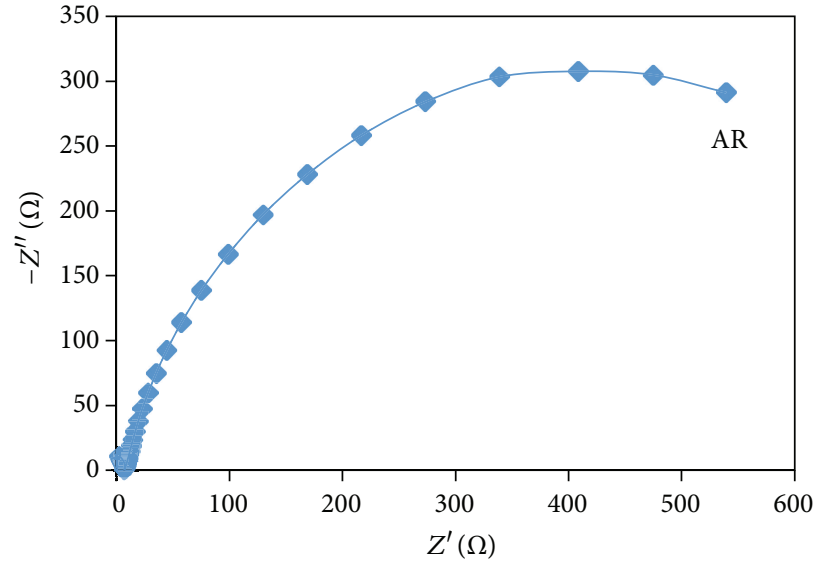

(a)

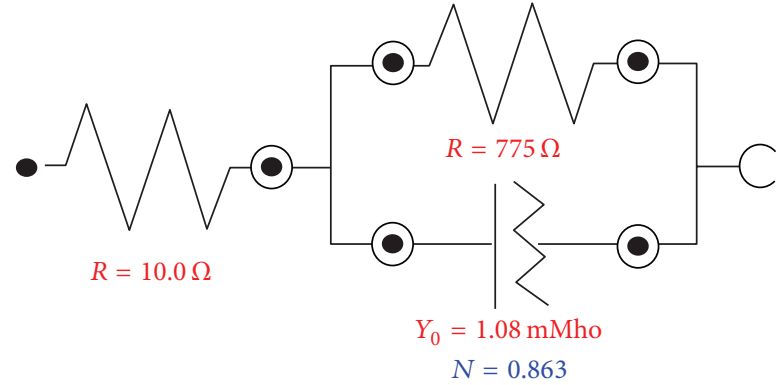

(b)

FIGURE 5: Determination of EIS parameters from the equivalent circuit (e.g., as received sample).

\section{Conclusions}

The effects of grain refinement on the corrosion of E34 microalloyed steel in different concentration of $\mathrm{NaCl}$ solutions after different microstructural conditions have been investigated. Due to repeated quenching from a temperature just below the lower critical temperature, the grain refinement of ferritic microalloyed steel has been achieved. Repeating the quenching up to three times led to yielding new grains at the expense of others, and a coarse grained material (as rolled) is replaced by the fine grained recrystallized structure. Corrosion rate $\left(I_{\text {corr }}\right)$ increases for repeated quenched samples implies that corrosion rate increases as grain refinement increases. The repeated quenching refines the grains, which renders greater anodic areas than coarser grained structure and thus activates the corrosion of steel. Corrosion potential $\left(E_{\text {corr }}\right)$ moves to more cathodic region indicates that the corrosion process is mainly accelerated by the cathodic reactions. The corrosion resistance, calculated from EIS results, shows the same trend as those obtained from polarization measurements. Results obtained from weight loss, dc polarization, and ac impedance techniques are in reasonably good agreement.

\section{Acknowledgment}

The author extends his appreciation to the Center of Excellence for Research in Engineering Materials (CEREM) of Advanced Manufacturing Institute, King Saud University, Riyadh, Saudi Arabia, for funding the work.

\section{References}

[1] I. A. Yakubtsov, P. Poruks, and J. D. Boyd, "Microstructure and mechanical properties of bainitic low carbon high strength plate steels," Materials Science and Engineering A, vol. 480, no. 1-2, pp. 109-116, 2008. 
[2] M.-C. Zhao, K. Yang, and Y.-Y. Shan, "Comparison on strength and toughness behaviors of microalloyed pipeline steels with acicular ferrite and ultrafine ferrite," Materials Letters, vol. 57, no. 9-10, pp. 1496-1500, 2003.

[3] F. Xiao, B. Liao, D. Ren, Y. Shan, and K. Yang, "Acicular ferritic microstructure of a low-carbon $\mathrm{Mn}-\mathrm{Mo}-\mathrm{Nb}$ microalloyed pipeline steel," Materials Characterization, vol. 54, no. 4-5, pp. 305-314, 2005.

[4] B. K. Panigrahi, "Processing of low carbon steel plate and hot strip-an overview," Bulletin of Materials Science, vol. 24, no. 4, pp. 361-371, 2001.

[5] R. Song, D. Ponge, D. Raabe, J. G. Speer, and D. K. Matlock, "Overview of processing, microstructure and mechanical properties of ultrafine grained bcc steels," Materials Science and Engineering A, vol. 441, no. 1-2, pp. 1-17, 2006.

[6] G. O. Oluwadare and O. Agbaje, "Corrosion of steels in steel reinforced concrete in cassava juice," Journal of Applied Sciences, vol. 7, no. 17, pp. 2474-2479, 2007.

[7] H. H. Uhlig and W. R. Revie, Corrosion and Corrosion Control. An Introduction to Corrosion Science and Engineering, John Wiley \& Sons, New York, NY, USA, 1985.

[8] H. Luo, Y. C. Guan, and K. N. Han, "Inhibition of mild steel corrosion by sodium dodecyl benzene sulfonate and sodium oleate in acidic solutions," Corrosion, vol. 54, no. 8, pp. 619-627, 1998.

[9] H. J. Cleary and N. D. Greene, "Corrosion properties of iron and steel," Corrosion Science, vol. 7, no. 12, pp. 821-831, 1967.

[10] X. Li, S. Deng, H. Fu, G. Mu, and N. Zhao, "Synergism between rare earth cerium(IV) ion and vanillin on the corrosion of steel in $\mathrm{H}_{2} \mathrm{SO}_{4}$ solution: weight loss, electrochemical, UV-vis, FTIR, XPS, and AFM approaches," Applied Surface Science, vol. 254, no. 17, pp. 5574-5586, 2008.

[11] D. T. Oloruntoba, O. O. Oluwole, and E. O. Oguntade, "Comparative study of corrosion behaviour of galvanized steel and coated $\mathrm{Al} 3103$ roofing sheets in carbonate and chloride environments," Materials and Design, vol. 30, no. 4, pp. 1371-1376, 2009.

[12] G. H. Aydoğdu and M. K. Aydinol, "Determination of susceptibility to intergranular corrosion and electrochemical reactivation behaviour of AISI 316L type stainless steel," Corrosion Science, vol. 48, no. 11, pp. 3565-3583, 2006.

[13] D. A. Hausmann, "Steel corrosion in concrete," Materials Protection, vol. 6, pp. 19-23, 1967.

[14] S. John, K. Mohammad Ali, and A. Joseph, "Electrochemical, surface analytical and quantum chemical studies on schiff bases of 4-amino-4H-1,2,4-triazole-3,5-dimethanol (ATD) in corrosion protection of aluminium in $1 \mathrm{~N}^{-} \mathrm{HNO}_{3}$, Bulletin of Materials Science, vol. 34, no. 6, pp. 1245-1256, 2011.

[15] H. H. Hassan, E. Abdelghani, and M. A. Amin, "Inhibition of mild steel corrosion in hydrochloric acid solution by triazole derivatives. Part I. Polarization and EIS studies," Electrochimica Acta, vol. 52, no. 22, pp. 6359-6366, 2007.

[16] P. Bommersbach, C. Alemany-Dumont, J. P. Millet, and B. Normand, "Formation and behaviour study of an environmentfriendly corrosion inhibitor by electrochemical methods," Electrochimica Acta, vol. 51, no. 6, pp. 1076-1084, 2005.

[17] I. L. Rosenfield, Corrosion Inhibitors, McGraw-Hill, New York, NY, USA, 1981.

[18] A. Subramania, A. R. Sathiya Priya, and V. S. Muralidharan, "Development of novel acidizing inhibitors for carbon steel corrosion in 15\% boiling hydrochloric acid," Corrosion, vol. 64, no. 6 , pp. 541-552, 2008.
[19] A. K. Singh, S. K. Shukla, M. Singh, and M. A. Quraishi, "Inhibitive effect of ceftazidime on corrosion of mild steel in hydrochloric acid solution," Materials Chemistry and Physics, vol. 129, no. 1-2, pp. 68-76, 2011.

[20] M. El Azhar, B. Mernari, M. Traisnel, F. Bentiss, and M. Lagrenée, "Corrosion inhibition of mild steel by the new class of inhibitors [2,5-bis(n-pyridyl)-1,3,4-thiadiazoles] in acidic media," Corrosion Science, vol. 43, no. 12, pp. 2229-2238, 2001.

[21] J. R. Macdonald, W. B. Johnson, and J. R. Macdonald, Theory in Impedance Spectroscopy, John Wiley \& Sons, New York, NY, USA, 1987.

[22] H. Wang, X. Wang, H. Wang, L. Wang, and A. Liu, "DFT study of new bipyrazole derivatives and their potential activity as corrosion inhibitors," Journal of Molecular Modeling, vol. 13, no. 1, pp. 147-153, 2007.

[23] A. Raman and P. Labine, Reviews on Corrosion Inhibitor Science and Technology, vol. 1, NACE, Houston, Tex, USA, 1986. 

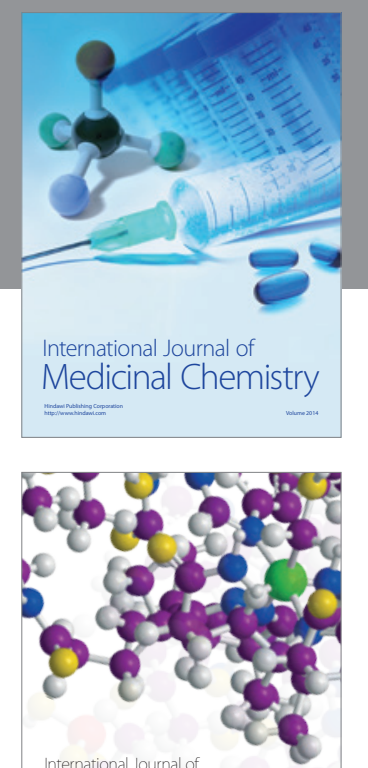

\section{Carbohydrate} Chemistry

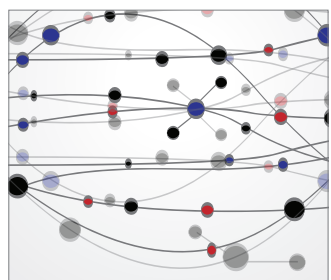

The Scientific World Journal
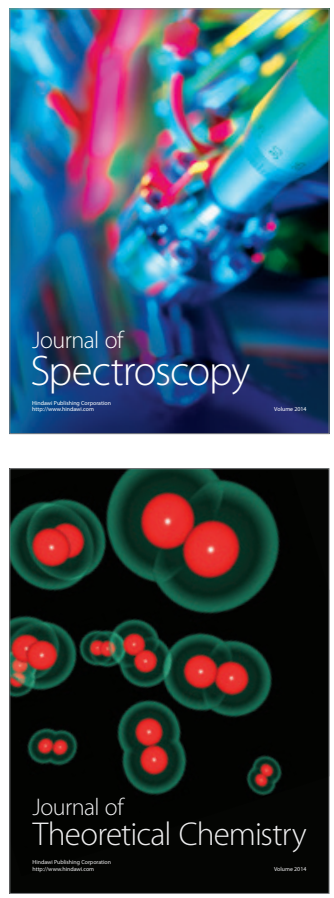
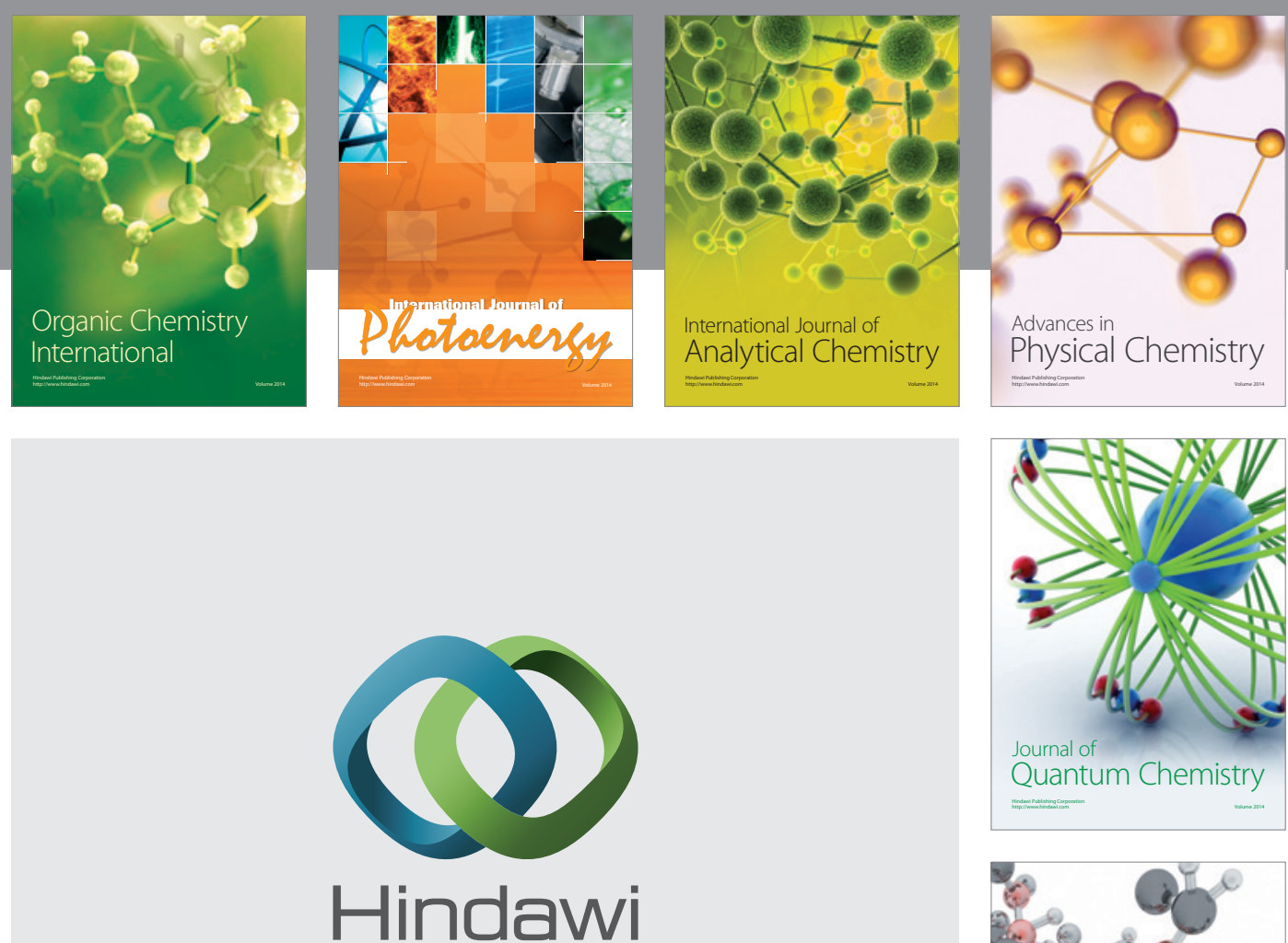

Submit your manuscripts at

http://www.hindawi.com

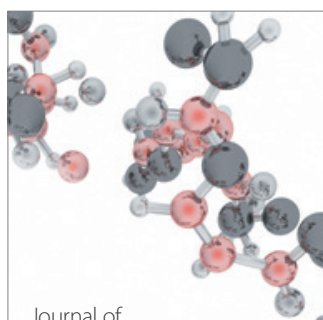

Analytical Methods

in Chemistry

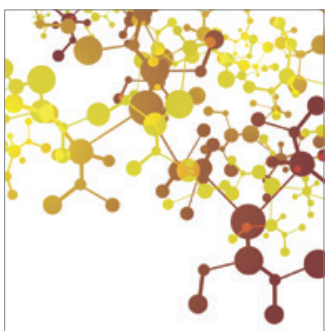

Journal of

Applied Chemistry

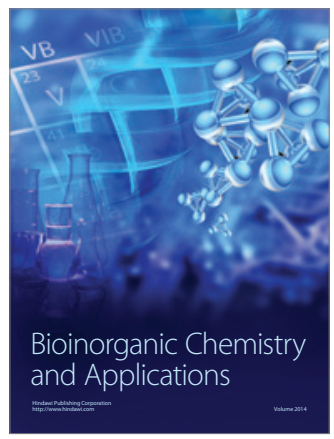

Inorganic Chemistry
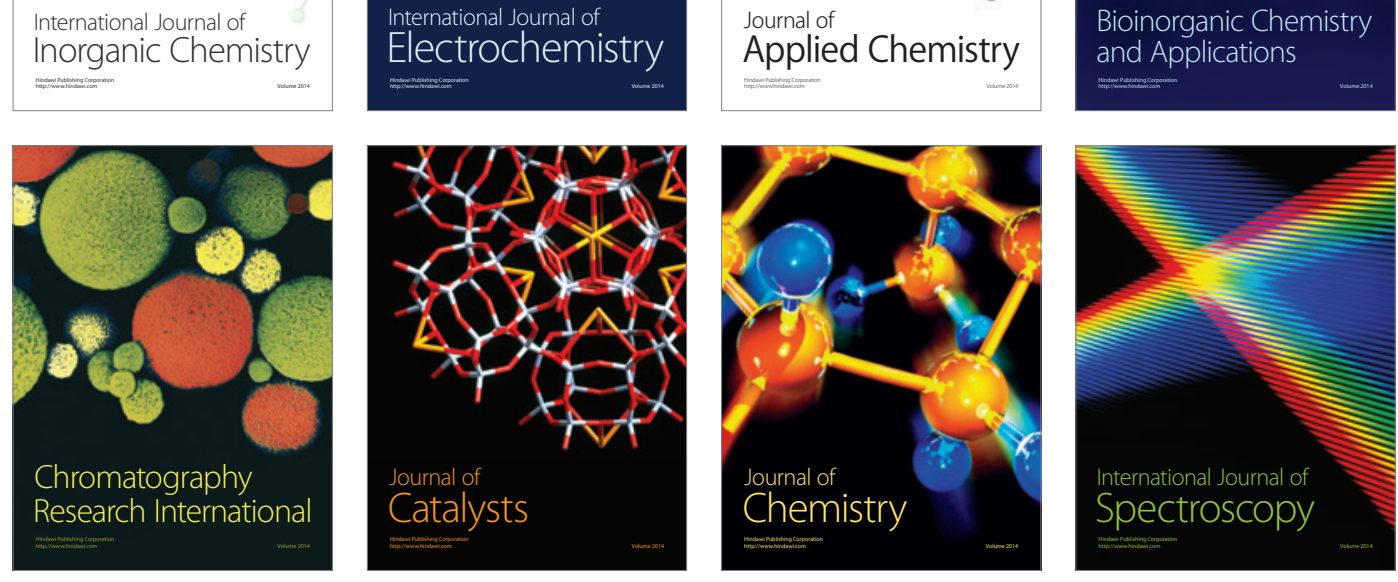